\title{
Retrieval of cirrus cloud optical thickness and top altitude from geostationary remote sensing
}

\author{
S. Kox ${ }^{1, *}$, L. Bugliaro ${ }^{1}$, and A. Ostler ${ }^{2}$ \\ ${ }^{1}$ Deutsches Zentrum für Luft- und Raumfahrt (DLR), Institut für Physik der Atmosphäre, Oberpfaffenhofen, Germany \\ ${ }^{2}$ Karlsruher Institut für Technologie, Institut für Meteorologie und Klimaforschung (IMK-IFU), Garmisch-Partenkirchen, \\ Germany \\ *now at: European Organisation for the Exploitation of Meteorological Satellites (EUMETSAT), Darmstadt, Germany
}

Correspondence to: S. Kox (stephan.kox@eumetsat.int)

Received: 20 February 2014 - Published in Atmos. Meas. Tech. Discuss.: 24 April 2014

Revised: 13 August 2014 - Accepted: 2 September 2014 - Published: 1 October 2014

\begin{abstract}
A novel approach for the detection of cirrus clouds and the retrieval of optical thickness and top altitude based on the measurements of the Spinning Enhanced Visible and Infrared Imager (SEVIRI) aboard the geostationary Meteosat Second Generation (MSG) satellite is presented. Trained with 8000000 co-incident measurements of the Cloud-Aerosol Lidar with Orthogonal Polarization (CALIOP) aboard the Cloud-Aerosol Lidar and Infrared Pathfinder Satellite Observations (CALIPSO) mission the new "cirrus optical properties derived from CALIOP and SEVIRI algorithm during day and night" (COCS) algorithm utilizes a backpropagation neural network to provide accurate measurements of cirrus optical depth $\tau$ at $\lambda=532 \mathrm{~nm}$ and top altitude $z$ every 15 min covering almost one-third of the Earth's atmosphere. The retrieved values are validated with independent measurements of CALIOP and the optical thickness derived by an airborne high spectral resolution lidar.
\end{abstract}

\section{Introduction}

High ice clouds hold an exceptional position within the large variety of clouds since they most probably generate positive net radiative forcing and therefore contribute to warming the Earth's atmosphere (Chen et al., 2000). Historically the family of cirrus clouds has been defined on the basis of visual observations by trained observers (Lynch et al., 2002). They appear at great altitudes in the upper troposphere and can visually be identified by their texture and colour. Cirrus clouds consist of ice particles and are often optically thin. The ice particles show various nonspherical shapes (see Weickmann, 1945; Bailey and Hallett, 2012). The basic microphysical conditions such as effective radius and ice water content, in addition to their low temperatures and high altitudes in the troposphere, have fundamental implications in terms of radiative transfer (Liou, 2002). The influence of cirrus clouds in general on the Earth's radiation budget is mainly dominated by their properties (i.e. coverage and optical thickness) as well as by sun zenith angle, surface albedo and temperature (Meerkötter et al., 1999). Concerning heating rates or radiative forcing the optical thickness of cirrus clouds is the key factor (Ackerman et al., 1988; Schumann et al., 2012).

Since 1983 the infrared and visible radiances of imaging radiometers carried on the international constellation of weather satellites have been collected in the International Satellite Cloud Climatology Project (ISCCP) (Rossow and Schiffer, 1999). As it is valid for all passive spaceborne instruments, especially those in geostationary orbits, Rossow and Schiffer (1999) state that the accuracy of the ISCCP cloud amount is determined by three factors: the accuracy and sensitivity of the cloud detection, and the accuracy of the areal cover fraction estimated by counting cloudy pixels with a finite resolution. In particular, the upper-level cloudiness is underestimated, which is caused by missed detections of very thin cirrus clouds (Wielicki and Parker, 1992). Rossow and Schiffer (1999) state that for the detectable limit of cloud cover fraction ( 0.1 over ocean and 0.15 over land), the lower detection limits for clouds are approximately $\tau=0.15$ over ocean and $\tau=0.25$ over land. 
Rossow and Schiffer (1999) analysed the ISCCP data set and found for cirrus clouds a global amount of $20 \%$ for the period from July 1983 to June 1994 - up to $21.1 \%$ in the tropics, while the northern and southern latitudes are covered by 20.7 and $16.8 \%$. Higher amounts of cirrus coverage were found by other polar-orbiting satellites. For example, the multispectral High Resolution Infrared Radiation Sounder (HIRS) aboard the NOAA polar-orbiting satellites detects up to $34 \%$ averaged global cirrus coverage (Wylie and Menzel, 1998). The tropics are covered with cirrus clouds by more than $90 \%$; high clouds are less dominant in higher latitudes with values of less than $40 \%$. The threshold of HIRS to detect clouds appears to be $\tau=0.1$. Based on 8 years of cloud properties retrieved from the Television Infrared Observation Satellite-N (TIROS-N) Observational Vertical Sounder (TOVS), Stubenrauch et al. (2006) calculated a global averaged cirrus coverage of $27.3 \%$, again with regional variations. Similar to HIRS, the TOVS instrument is sensitive to clouds with low optical thickness (with a detection limit of $\tau=0.1$ (Stubenrauch et al., 2006; Wylie et al., 1995).This high variability is caused by the different detection sensitivities of the different sensors, which is confirmed by the highly variable global average fraction of high-level clouds - ranging from 12 to $55 \%$ (Stubenrauch et al., 2013).

Coverage and optical properties of ice clouds can also be derived by measurements of geostationary satellites equipped with passive instruments - for example METEOSAT Second Generation (MSG) carrying the Spinning Enhanced Visible and Infrared Imager (SEVIRI), which covers about onethird of the Earth's atmosphere from $80^{\circ} \mathrm{N}$ to $80^{\circ} \mathrm{S}$ and from $80^{\circ} \mathrm{W}$ to $80^{\circ} \mathrm{E}$ with a resolution of $3 \mathrm{~km} \times 3 \mathrm{~km}$ at subsatellite point repeating its measurements every $15 \mathrm{~min}$. For instance, in order to detect cirrus clouds the METEOSAT Cirrus Detection Algorithm 2 (MECiDA 2) uses the thermal infrared channels of SEVIRI and combines morphological and multi-spectral threshold tests (Krebs et al., 2007; Ewald et al., 2013). Krebs et al. (2007) showed an average cirrus coverage of $29.3 \%$ for a Northern Hemispheric region $\left(80^{\circ} \mathrm{W}\right.$ to $50^{\circ} \mathrm{E}, 20$ to $\left.60^{\circ} \mathrm{N}\right)$ in the year 2004 . Furthermore, this method was successfully applied in order to identify aviation-induced cirrus cover in the Northern Atlantic flight corridor (Graf et al., 2012). Nevertheless, this algorithm is found to have low detection sensitivity to cirrus clouds with low optical thickness $(\tau \leq 0.5)$ and therefore underestimates cirrus coverage. In order to characterize the properties of the detected cirrus clouds, MECiDA 2 is combined with a wellknown method to retrieve the optical thickness of a cloud with passive remote sensing instrument, adopted from Nakajima and King (1990). It uses the properties of reflected sunlight in the visible and near-infrared SEVIRI channels centred at 0.6 and $1.6 \mu \mathrm{m}$ (APICS, Algorithm for the Physical Investigation of Clouds with SEVIRI, described in Bugliaro et al., 2011) and therefore cannot retrieve optical properties during night-time.
Nowadays active spaceborne remote sensing provides the capability to obtain vertical profiles of the Earth's atmosphere with high vertical resolution, in line with the global determination of cloud top height, cloud bottom height, multilayer cloud structure, and planetary boundary layer height in combination with different optical properties of aerosols and clouds (Palm, 2005). In April 2006 the CloudAerosol Lidar and Infrared Pathfinder Satellite Observations (CALIPSO) mission was launched carrying the CloudAerosol Lidar with Orthogonal Polarization (CALIOP). Based on different scene classifications and retrieval algorithms in combination with auxiliary data sets, CALIOP provides highly accurate measurements of different optical and physical properties of e.g. cirrus clouds from a polar orbit with a footprint of about $100 \mathrm{~m}$ along and $90 \mathrm{~m}$ cross track and a vertical resolution of up to $30 \mathrm{~m}$ (Winker et al., 2002; Vaughan et al., 2004) with the typical limitations of a lidar. In the case of CALIOP the vertical structure and therefore the retrieval of i.e. cloud bottom height is only possible if the cloud is optically thin and the lidar signal is not saturated. Since CALIOP is no High Spectral Resolution Lidar (HSRL), a LIDAR ratio defined as the ratio of extinction to backscatter coefficient, $S=\frac{\alpha}{\beta}$, has to be applied in order to retrieve the vertical integrated optical thickness. In the case of cirrus clouds this LIDAR ratio is assumed and depends on the modelled atmospheric temperature. With this LIDAR ratio the optical thickness $\tau$ can be calculated as

$\tau=\int_{r_{0}}^{r_{1}} \alpha(r) \mathrm{d} r$,

where $r$ is the range from the lidar and $r_{0}$ and $r_{1}$ are the range from the lidar to the lower and to the upper limit of the identified layer.

But due to the repeat cycle of 16 days, the CALIOP instrument is unable to retrieve information on life cycles and diurnal cycles of atmospheric features such as cirrus clouds. Nevertheless, the high sensitivity of CALIOP leads to a cloud fraction of up to $70 \%$ (Nazaryan et al., 2008).

Therefore a new approach was followed to combine the advantages of polar-orbiting active and geostationary passive remote sensing (high sensitivity and accuracy of CALIOP with the high temporal resolution and spatial coverage of SEVIRI): the cirrus optical properties derived from CALIOP and the SEVIRI day and night (COCS) algorithm based on an artificial neural network, which retrieves cirrus optical thickness and cloud top altitude from the thermal infrared channels of SEVIRI allowing day and night observations. The network is trained by coincident CALIOP cirrus optical thickness and top altitude. This paper describes the algorithm and its validation against airborne and spaceborne lidar measurements as well as a comparison with well-known passive algorithms based on measurements of SEVIRI. 
This paper is organized as follows: Sect. 2 gives an overview of both satellites used and their main instruments. Section 3 describes the basic theory of a backpropagation neural network and the COCS algorithm, followed by some examples in Sect. 4. In Sect. 5 the validation with CALIOP itself and an airborne HSRL is provided. Section 6 provides exemplary results of time series processed with COCS. A summary and conclusions are presented in Sect. 7 .

\section{Remote sensing of cirrus clouds}

\subsection{CALIOP aboard CALIPSO}

Launched in April 2006, the CALIPSO mission provides global observations of aerosol and cloud properties with its onboard lidar CALIOP amongst other instruments. CALIPSO flies as a part of the National Aeronautic and Space Administration (NASA) afternoon constellation (ATrain) together with Aqua, CloudSat, PARASOL and Aura. CALIPSO was launched into a polar orbit of $705 \mathrm{~km}$ with a repeat cycle of 16 days. All satellites together provide quasisimultaneous measurements of aerosols, clouds, relative humidity, temperature, and radiative fluxes for the first time (Winker et al., 2002).

For this purpose CALIOP uses a Nd: YAG laser emitting pulses at wavelengths of 1064 and $532 \mathrm{~nm}$ with a spatial distance of $333 \mathrm{~m}$ between two vertical profiles each with a footprint of $100 \mathrm{~m}$ along and $90 \mathrm{~m}$ cross track (Winker et al., 2007). As with ground-based depolarization lidar, CALIOP relies on polarization information to determine cloud phase based on the assumption that water cloud particles are spheres and ice clouds are composed of non-spherical particles (Hu et al., 2009). Beside vertical profiles of aerosols, CALIOP delivers vertical profiles of clouds, primarily from the $532 \mathrm{~nm}$ channels with a vertical resolution of up to $30 \mathrm{~m}$. In order to identify aerosol and cloud layers and to retrieve their optical and microphysical properties several algorithm are applied (Vaughan et al., 2004, 2005, 2008; Winker et al., 2009). In this work we focus on two properties of known cirrus clouds and cirrus cloud layers, respectively: the cloud top height, $z$, and the optical thickness of a cirrus cloud at $532 \mathrm{~nm}, \tau_{532}$.

Several attempts to validate the retrieved cirrus cloud properties of CALIOP were accomplished in the past few years. Rogers et al. (2011) used measurements from the NASA Langley Research Center HSRL in June 2006 to validate the $532 \mathrm{~nm}$ total attenuated backscatter measurements. The CALIOP measurements were found to agree to the backscatter coefficients derived by the HSRL with a slight underestimation of $2.7 \% \pm 2.1 \%$ during night and $2.9 \% \pm 3.9 \%$ during daytime.

During the CIRCLE-2 experiment in May 2007 the extinction coefficients for thin cirrus clouds derived by CALIOP were compared to in situ measurements of a Polar Neph- elometer aboard the DLR Falcon research aircraft (Mioche et al., 2010). Both extinction coefficients were found to agree (slope parameters of the linear fits greater than 0.9) with a very good correlation for thin cirrus clouds with extinction coefficients between 0.6 to $1.2 \mathrm{~km}^{-1}$ for irregular-shaped ice crystals. On the other hand an overestimation of the CALIOP extinction coefficients was found due to pristine-plate crystals with sizes up to $300 \mu \mathrm{m}$. In order to avoid subsequent biases in CALIPSO retrieval products, the CALIOP laser beam has been tilted $3^{\circ}$ ahead of the nadir direction since November 2007. Most recently Hlavka et al. (2012) published validation results on cirrus cloud optical properties derived from CALIOP measurements during the CALIPSOCloudSat Validation Experiment (CC-VEX). Compared to the airborne Cloud Physics Lidar (CPL) differences in the resulting optical thickness of only $\sim 7 \%$ for the values derived by CALIOP were found in the case of agreeing lidar ratios. However, in the case of disagreeing lidar ratios of both systems, the resulting optical depth difference is significant (31\%).

\subsection{SEVIRI aboard MSG}

The METEOSAT Second Generation (MSG) program consists of four equal satellites (MSG-1, MSG-2, MSG-3, MSG4), which were developed for meteorological observations of the Earth's atmosphere until at least 2018 (Schmetz et al., 2002). The satellites are operated in a geostationary orbit at an altitude of around $36000 \mathrm{~km}$ with their main instrument, the Spinning Enhanced Visible and Infrared Imager (SEVIRI) covering one-third of the Earth's surface with its 12 spectral channels. The 11 low-resolution channels cover the whole "Earth disc" from around $80^{\circ} \mathrm{N}$ to $80^{\circ} \mathrm{S}$ and $80^{\circ} \mathrm{W}$ to $80^{\circ} \mathrm{E}$ every $15 \mathrm{~min}$ with a sampling distance of $3 \mathrm{~km}$ at subsatellite point decreasing to around $4 \mathrm{~km} \times 5 \mathrm{~km}$ over Central Europe. This resolution decreases for growing viewing zenith angle due to the curvature of the Earth's surface. In order to allow for day- and night-time observations of the atmosphere SEVIRI is suited with seven channels in the thermal infrared with wavelengths from around 6 to $14 \mu \mathrm{m}$.

\section{Methodology}

Based on a neural network the high spatial coverage during day and night by SEVIRIs infrared channels is combined with the high accuracy of the spaceborne lidar measurements of CALIOP in order to derive properties of thin cirrus clouds.

\subsection{Neural network}

Comparable to Aires et al. (2001) and Blackwell (2005), who used feed-forward neural networks to derive e.g. temperature, moisture, liquid water path, or surface temperature from remote sensing data, we use a neural network approach in order to retrieve cirrus optical thickness and cirrus top altitude. 


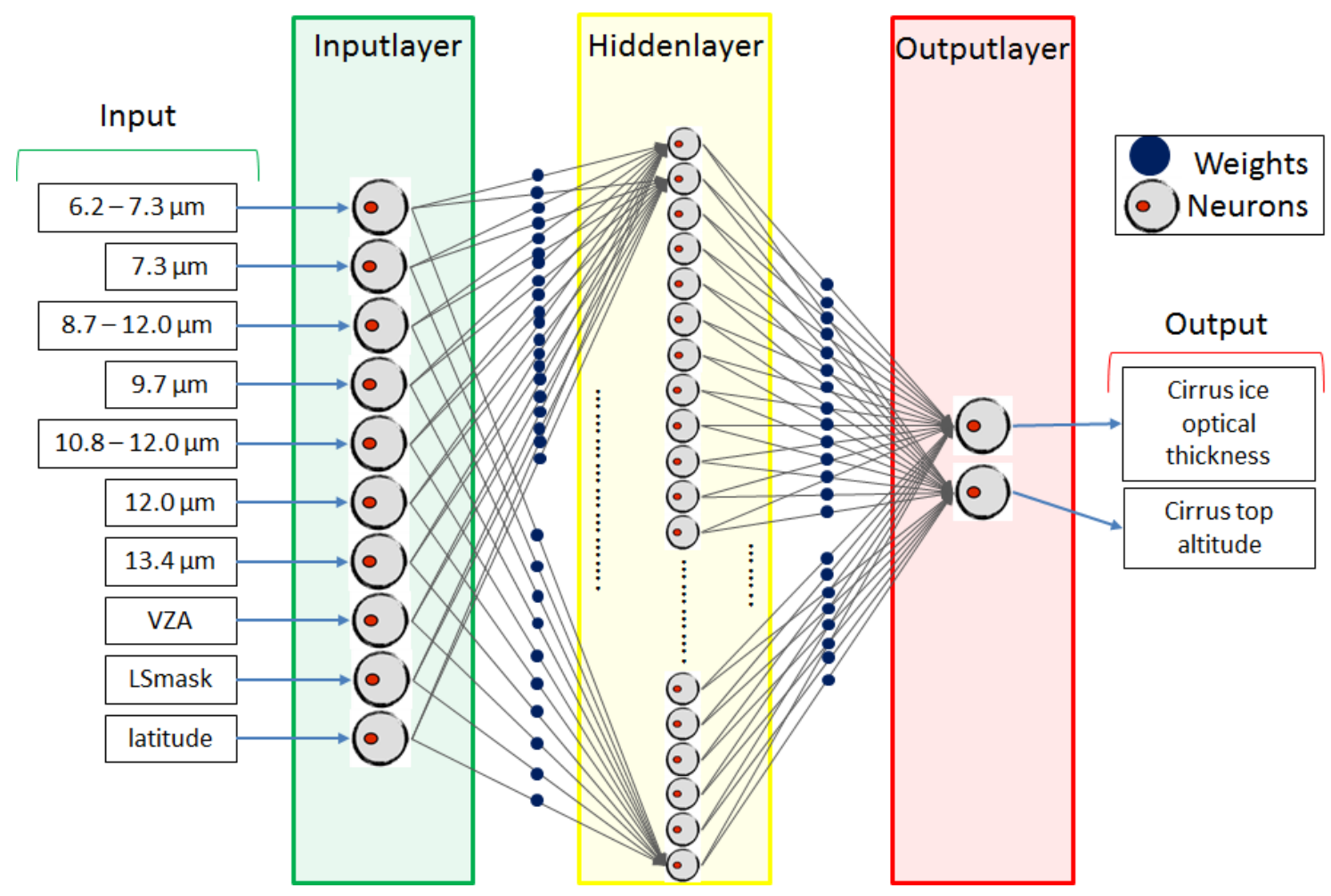

Figure 1. Scheme of the general setup of the backpropagation neural network for COCS and its input and output data sets. The different layers of the neural networks are shaded green, yellow and red for the input-, the hidden-, and the output layer respectively. The connections between each of the neurons of one layer to each neuron of the next layer are sketched by arrows, while the weight of each connection is stylized by a blue dot. The different inputs of COCS are shown on the left, the outputs on the right.

In general, artificial neural networks consist of several neurons that are used to gather information from outside the neural network, or from other neurons, and to send this information back to a receiver or receptor in a modified way or again to other neurons. These neural networks consist of three different types of neurons: input neurons, hidden neurons and output neurons:

- Input neurons: neurons that receive signals (stimuli, pattern, etc.) from outside the neural network, possibly from nature.

- Hidden neurons: neurons between input and output neurons; internal representation of environment.

- Output neurons: neurons to transmit signals to a receiver or receptor. They combine the signals from the hidden layer(s).

Neurons are combined in layers (Fig. 1). The neurons of the input layer are connected to the neurons of the hidden layer, which are in turn connected to the output layer neurons. The strength of the connection between two neurons is defined by a weight. The higher its value the greater is the influence of one neuron on the other. Those weights represent the "memory" of an artificial neural network. In order to modify these weights and to optimize the neural network, we use the backpropagation of errors, well explained by Rumelhart et al. (1986). Therefore a large data set, the "training data set", is used to modify the memory of the neural network or to be more exact to minimize the error of the neural network. Once the training of the neural network with this data set is finished, it is repeated to minimize the error between the calculated results and the target values in an iterative approach. Depending on the information and quality of the training data set as well as on the number of weights to be determined, several thousand of such iterations are needed until the error is as low as possible. The training data set of COCS consists of three data sets: the cirrus optical thickness $\tau$ and the cirrus top height $z$ derived from CALIOP, seven different infrared brightness temperatures and brightness temperature differences measured by SEVIRI, and so-called auxiliary data, such as latitude, viewing zenith angle of SEVIRI, and a land-sea mask. The data set consists of nine million collocated measurements of SEVIRI and CALIOP for the timespan from July 2006 to June 2009.

\subsection{The CALIOP training data set}

As explained in Sect. 2.1, cirrus cloud optical thickness $\tau$ and top altitude $z$ are derived from the CALIOP $5 \mathrm{~km}$ cloud layer product. These measurements are here used as the so-called 
target values. During preliminary analysis, the cloud layer products in version 2.01 and 2.02 were found to contain some inaccurate classifications, in which cirrus-free parts of the atmosphere were labelled as cirrus clouds. Furthermore, a well-known CALIOP retrieval behaviour had to be taken into account. In general, the extinction quality flag is reported for each cloud layer where an extinction coefficient was calculated by the CALIOP retrieval. This flag contains information about whether the extinction retrieval is constrained or unconstrained, which is the case for example when the layer is elevated above a water cloud or as in the case of the anvil of a cumulonimbus, where no spatial separation exists between the water and ice phase of the cloud. It also indicates whether the lidar ratio was reduced or increased. Figure 2 shows a histogram of the ice optical thickness of the $5 \mathrm{~km}$ cloud layer product with a bimodal distribution. The right peak at $\tau \sim 2.5$ appears to be an artefact of the CALIOP retrieval algorithm, when the initial retrieval diverges and the lidar ratio is reduced in order to produce a convergent solution. In most cases this happens in totally attenuating, opaque clouds, when the true cirrus lidar ratio is significantly smaller than the initial value assumed by the algorithm (Atmospheric Science Data Center, 2011). If the lidar ratio is kept unchanged the extinction quality flag is reported with values greater than or equal to 1 . The absorption of an aerosol or cloud layer increases until the signal gets totally attenuated and CALIOP fails to penetrate through the specific layer. This behaviour is observed for optical thickness $\tau$ greater than 3-5 (Winker et al., 2010).

In order to remove these false alarms from the training data set, the CALIOP data have been filtered according to the following criteria: a first criterion takes the accuracy of the retrieved cloud properties derived by the CALIOP algorithm into account. Since the main focus of the COCS algorithm is on thin cirrus clouds the maximum value of the ice optical thickness of a cirrus layer can therefore be limited to $\tau=2.5$. Another important factor in the lidar measurements is the distinction between ice (i.e. cirrus) over water clouds. CALIOP does well in separating cirrus clouds overlying deeper water clouds. In the case of a cumulonimbus cloud with a cirrus top, this cloud is generally flagged as cirrus.

Secondly, the mid-layer temperature as a part of the CALIOP cloud layer product, which is calculated for each layer at its geometric midpoint, is used as another filter criterion. By testing and analysing the statistics of the CALIOP data set an optimal threshold for the mid-layer temperature of the detected cirrus layer was found to be $243 \mathrm{~K}$ in order to achieve a low frequency of misclassification. Finally, another threshold is applied that aims to prevent aerosol layers being classified as cirrus clouds, which happens over tropical maritime regions at low altitudes. The threshold limit is a simple approach based on the atmospheric profile depicted in Fig. 3. In high-altitude regions it assumes that the cirrus cloud temperature of $243 \mathrm{~K}$ can be reached at altitudes of $4.5 \mathrm{~km}$, while this altitude raises up to $9.5 \mathrm{~km}$ in tropical regions. Thus, only cirrus with cloud altitudes above $z_{\text {top, min }}$ are taken into account. Therefore, for absolute values of latitude |lat| greater than $22^{\circ}$ the minimum top altitude $z_{\text {top,min }}$ of a cirrus can be calculated as

$z_{\text {top }, \min }($ lat $)=4.5 \mathrm{~km}+(5.0 \mathrm{~km})\left(\frac{80.0-|\mathrm{lat}|}{58.0}\right)$.

For latitudes with $\mid$ lat $\mid \leq 22^{\circ}$ the threshold altitude is kept constant at a value of limit top $($ lat $)=9.5 \mathrm{~km}$.

\subsection{The SEVIRI training data set}

As COCS is intended to detect cirrus clouds during day and night time the thermal infrared channels of SEVIRI are used as input for the neural network. Hence, infrared brightness temperatures (BT) of the channels WV073, IR097, IR120, and IR134 are selected as well as the brightness temperature differences (BTD) of the channel combinations WV062 and WV073, IR087 and IR120, and IR108 and IR120. In order to support the error minimization within the backpropagation neural network three BTDs were chosen complementary to the four BTs, since their sensitivity to cirrus cloud properties has been already shown (Liou, 1977; Szejwach, 1982; Menzel et al., 1983; Wylie and Menzel, 1989; Inoue, 1985; Krebs et al., 2007). Another possibility is the use of the seven thermal BTs, but the combination of the four BTs and the three BTDs was found to maximize the speed of training of the neural network and to minimize the error in the final version of COCS.

\subsection{Auxiliary data}

In addition to CALIOP and SEVIRI data, COCS uses three auxiliary data sets: latitude, viewing zenith angle of SEVIRI, and a land-sea mask. The viewing zenith angle gives the algorithm information on the resolution of SEVIRI and the slant path through the atmosphere, which decreases with growing viewing zenith angle, while the latitudes support COCS to correctly determine the correct top altitude of cirrus clouds, which are highest within the ITCZ and lowest in regions at high latitudes. The land-sea mask is based on a map with a $0.5^{\prime}$ resolution in latitude and longitude $(\approx 0.2 \mathrm{~km})$ derived by the Group for High Resolution Sea Surface Temperature (Kaiser-Weiss, 2011), and covers latitudes from $80^{\circ} \mathrm{N}$ to $80^{\circ} \mathrm{S}$.

\subsection{Data set splitting}

Before May 2008 the calibrated radiances of the infrared channels of SEVIRI were provided as spectral radiances. Brightness temperatures had therefore to be calculated by inverting the Planck function at the central wavelength of the channels. From May 2008 the radiances definition was changed so that it now represents the "effective radiance" over the instrument spectral response (EUMETSAT, 2007), 


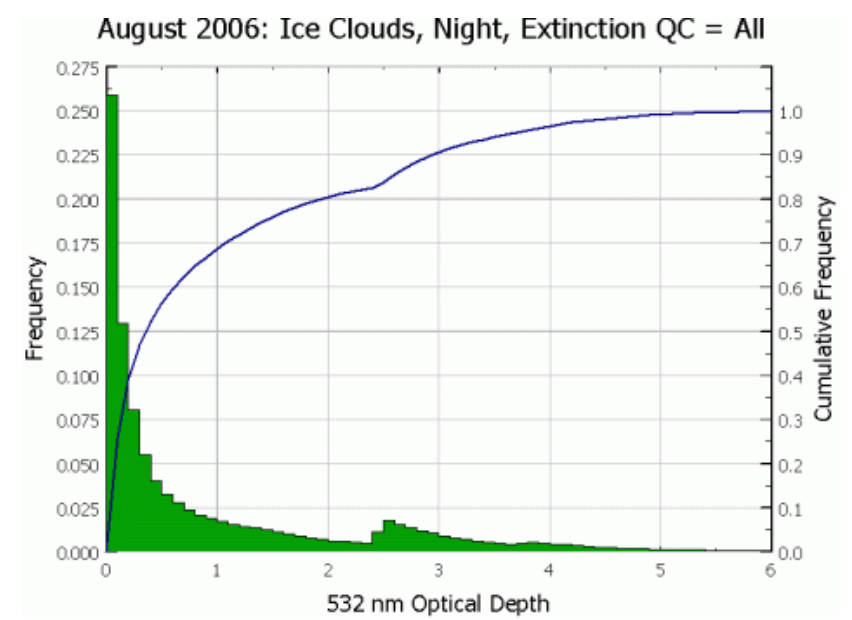

Figure 2. Histogram of ice optical thickness retrieved from CALIOP in August 2006 during night-time (Atmospheric Science Data Center, 2011) based on data covering all extinction quality flags (unfiltered).

taking into account that the sensitivity of each channel also changes within its bandwidth. This change in the radiance calculation results in differences of the retrieved brightness temperatures in each channel.

To date, the archive at DLR contains data with both definitions. Thus, the data set is divided into two parts and two different neural networks are trained and applied. The first covers the period from July 2006 to April 2008 (period 1). The second data set covers the time from May 2008 to June 2009 (period 2). Secondly, the two data sets of SEVIRI brightness temperatures, auxiliary data, and CALIOP measurements are split once again. For both periods a total of 8 million measurements are used to train the two neural networks. Additionally, 1 million measurements are separated from the training data set and used for further validation and testing of COCS, which is again separated into two test data sets according to the periods defined above with roughly 500000 points per period.

\subsection{Setup of the neural network}

Before the training of the backpropagation neural network is initialized, the final setup of COCS needs to be determined. Therefore, 10 neurons in the input layer (the seven BTs and BTDs of SEVIRI and the auxiliary data) and two neurons in the output layer (cirrus ice optical thickness and top altitude) are set by the input and output data set. The number of hidden neurons was chosen by considering two properties of the neural network. On the one hand, more hidden layer neurons generate more accurate results. On the other hand, neural networks with fewer neurons perform faster. Since the final algorithm should perform as fast as possible in combination with sufficient accuracy as seen in the later validation (Sect. 5), a level of 600 neurons for the hidden layer has been
Distribution of Cirrus Top Altitude, CALIOP, January 2008

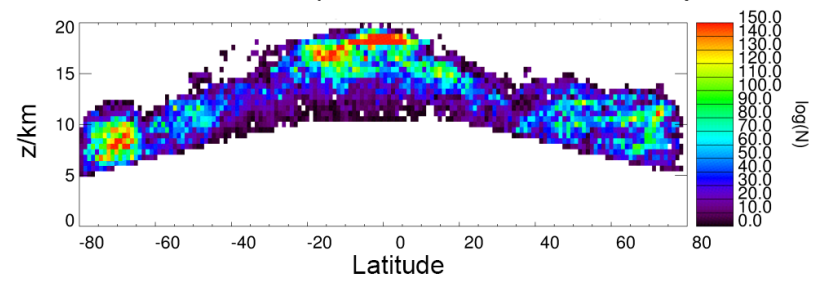

Figure 3. Cirrus top altitude distribution after applying the filter criteria described in Sect. 3.2 for January 2008.

found to be a good trade-off by empirically testing different setups. This leads to 6000 connection weights between input and hidden layer and 1200 weights between hidden and output layer. Each of the chosen inputs, i.e. the BTs and BTDs as well as the auxiliary data, have different influence on the weight of each of the connections between the neurons of each layer. In Fig. 4 the relative weight of each of the input variables is depicted in percent. The highest relative weight is found in the BT of the T134 channel, followed by the BT of T120 and the BTD of T087 and T120 together with auxiliary data such as viewing zenith angle and latitude. The smallest weight has the land-sea mask, while the BTs of the T073 and T097 channels still have a significant weight.

\subsection{Collocation and parallax-correction}

CALIOP and SEVIRI data are spatially and temporally collocated for each overpass. Collocation in time and space is necessary in order to guarantee that both satellite instruments observe the same cloud at the same time. The time of each atmospheric profile in the $5 \mathrm{~km}$ cloud layer product of CALIOP is compared to the imaging time of SEVIRI and the closest time slot of SEVIRI is chosen to minimize the temporal deviation. As SEVIRI has a repeat cycle of $15 \mathrm{~min}$ a maximum difference of approximately $7.5 \mathrm{~min}$ remains. As the radiometer scans away from the subsatellite point, the effective resolution of SEVIRI data is decreased due to the curvature of Earth and the increasing distance to the satellite. The cloud is detected by SEVIRI with a so-called parallax displacement. Depending on the viewing zenith angle and on the altitude of the cloud, its displacement compared to its correct position "over ground" can be calculated by using latitude, longitude and the top altitude of the cirrus layer (Radová and Seidl, 2008). CALIOP latitude and longitude are directly translated to the SEVIRI pixel grid, while the cirrus top altitude is directly measured by CALIOP. With this information the parallax displacement is corrected and the exact SEVIRI pixel is chosen for the cirrus cloud detected by CALIOP. The CALIOP data provide a horizontal resolution of $5 \mathrm{~km}$ with a narrow cross-section of the lidar footprint of $90 \mathrm{~m}$. Each $5 \mathrm{~km}$ of the cloud layer product is achieved by averaging 15 single vertical profiles (Fig. 8). A SEVIRI pixel is around $3 \mathrm{~km} \times 3 \mathrm{~km}$. While one SEVIRI pixel covers at least 


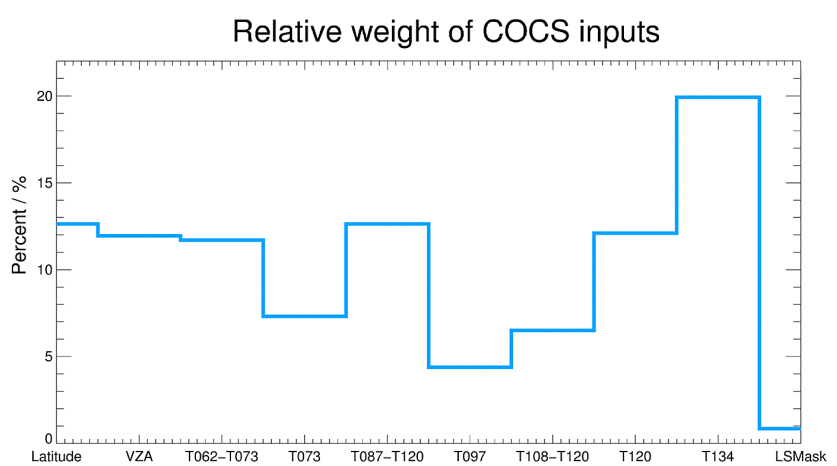

Figure 4. The relative weight of the single COCS inputs in percent, from right to left: latitude, viewing zenith angle (VZA), followed by the single BTs and BTDs, and the land-sea mask (LSMASK).

an area of $9 \mathrm{~km}^{2}$ at subsatellite point, CALIOPs $5 \mathrm{~km}$ Product only "cuts" through a small part of the cloud within one SEVIRI pixel. The sampling area used in the SEVIRI data processing to reduce radiometric noise of each SEVIRI pixel is even greater.

\subsection{Training the neural network}

The training of COCS follows the steps described in Sect. 3.1, whereby the training data set is presented to the network in random order until no change in the performance expressed by the sum of the quadratic deviations is observed. This error was minimized until no further improvement in the results was achieved, reaching a standard deviation according to Eq. (3) of $\sigma_{\tau}^{2}=0.3$ and $\sigma_{z}^{2}=0.8 \mathrm{~km}$ for both neural networks, COCS period 1 and COCS period 2. These deviations are further analysed in Sect. 5 .

\section{COCS examples}

Once the training is finished, COCS is applied to SEVIRI measurements. For each $15 \mathrm{~min}$ time slot of SEVIRI with $3712 \times 3712$ pixels the processing of $\tau$ and $z$ takes around $600 \mathrm{~s}$ on a common office desktop computer including the preprocessing of the SEVIRI input data. In the false colour composite of SEVIRI (Fig. 5a) three different channels (VIS006, VIS008, IR108) are combined to give an overview of several atmospheric features on the 11 September 2010 at 15:00 UTC. Water clouds are coloured in light yellow and grey, while ice clouds appear in white and light blue/violet. The belt of the Innertropical Convergence Zone (ITCZ) is covered by a relatively high amount of cirrus clouds, while the northern and southern parts of the African continent show only small amounts of cirrus clouds. Two tropical cloud cluster are detected over the Atlantic west of Africa and the Caribbean Sea. Another tropical storm is located north of Madagascar, which is not clearly visible due to the sunset at the eastern limits of the MSG disc. Southwest of Africa maritime stratocumulus clouds cover wide areas. The southernmost Atlantic is strongly covered with cirrus clouds, while a mix of water and ice clouds is present north of the equator. Frontal systems over Europe and the North Atlantic are visible.

In Fig. $5 \mathrm{~b}$ and $\mathrm{c}$ the results of COCS $\tau_{\mathrm{COCS}}$ and $z_{\mathrm{COCS}}$ are shown for the same time slots with coastlines to give a better orientation. The cirrus clouds described above can qualitatively be identified in both figures. The ITCZ, the tropical cyclone, and even the frontal systems appear to have varying optical thickness and top altitude. It is remarkable that both variables obviously show no influence of whether the underlying surface is sea or land. The algorithm succeeds in detecting ice clouds, while water clouds like the maritime stratocumulus clouds west of Namibia and Angola remain undetected. Especially the large cirrus cloud field south of Greenland over the North Atlantic is noteworthy. The North Atlantic Region and parts of Europe are enlarged (Fig. 5d and e). A large cirrus cloud field reaches from the coast of the United States almost to the south of Iceland. Obviously fine structures of the cirrus clouds are present with top altitudes reaching from 8 to $13 \mathrm{~km}$ and cirrus optical thickness up to 2.3. Additionally, the centre of a low-pressure area can be found north of the UK together with small amounts of cirrus clouds over Morocco. Figure 5 aims to exemplify the application of COCS and to give an idea on the provided resolution. As one can see, different structures of cirrus clouds are found in different regions of the MSG disc containing clouds with highly variable cirrus optical thickness and top altitude.

\section{Validation and comparison}

\subsection{CALIOP}

In order to test the performance of the COCS algorithm, one ninth of the training data set is separated as an independent test data set and has therefore no influence on the training of COCS. It is used for the validation with CALIOP in the following. Fig. 6 compares the cirrus optical thickness $\tau_{\text {COCS }}$ to the CALIOP measurements $\tau_{\text {CALIOP }}$ shown as a two-dimensional histogram on a logarithmic scale. COCS period 1 (left panel) shows an overall good performance. However, COCS period 1 tends to underestimate the cirrus optical thickness for $\tau_{\text {CALIOP }}>1.7$, while for $\tau_{\text {COCS }} \leq 1.0$ a slight overestimation of the cirrus optical thickness compared to the results of CALIOP is present. COCS period 2 (right) may result in a higher accuracy possibly caused by EUMETSAT's updated definition for measured radiances in order to retrieve brightness temperatures (Sect. 3), but since both data sets (period 1 and 2) differ in size no final statement can be given here. For low values a high agreement of $\tau_{\text {CALIOP }}$ and $\tau_{\text {COCS }}$ is found. For $\tau_{\text {CALIOP }} \geq 2.0$ only low deviations are found. The tendency to underestimate high 

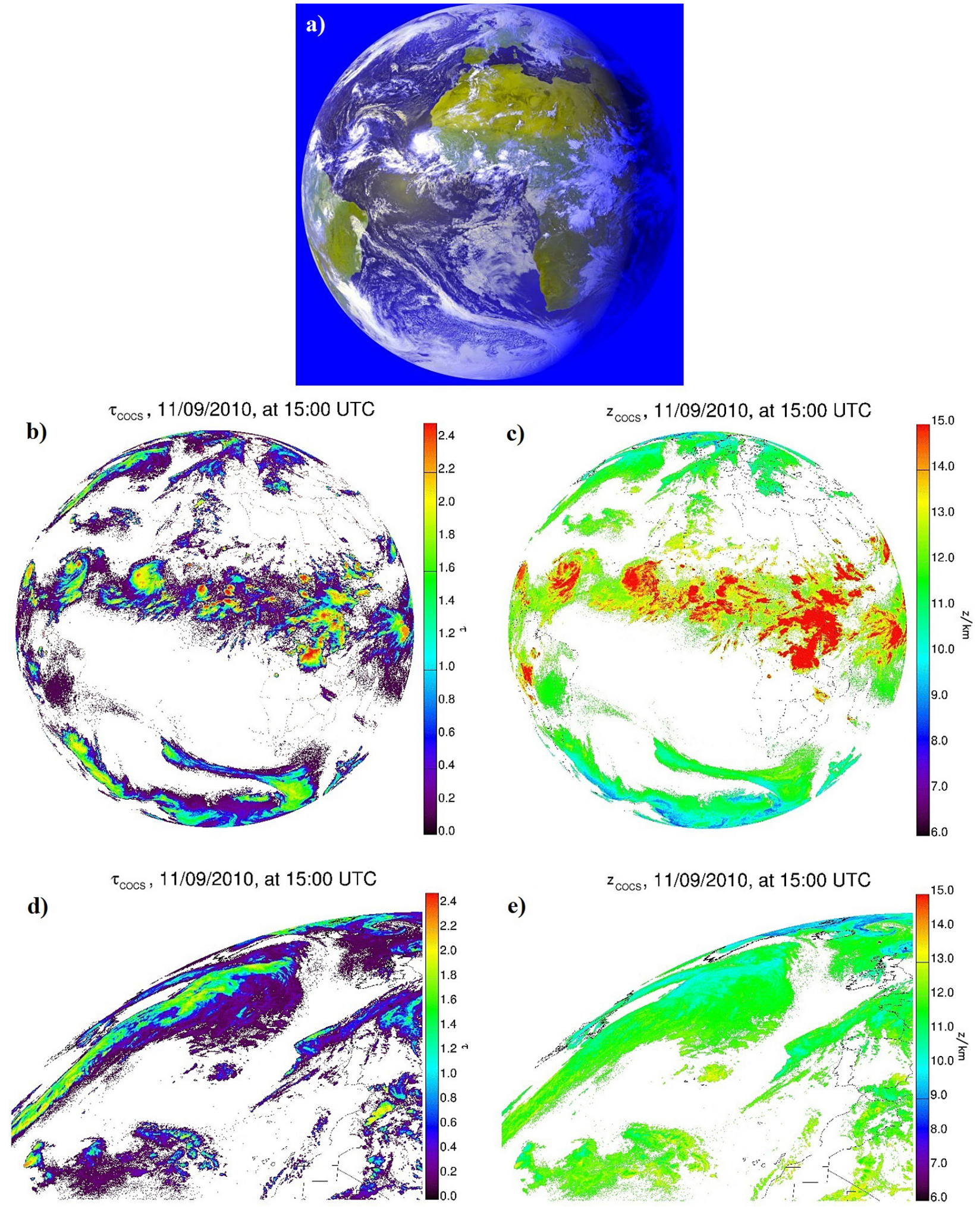

Figure 5. False colour composite of SEVIRI (VIS006, VIS008, IR108) at 15:00 UTC on 11 September 2010 (a). Ice optical thickness $\tau$ (b) and top altitude $z$ (c) of cirrus clouds retrieved by COCS at 15:00 UTC on 11 September 2010. For the same time slot an enlarged view on the North Atlantic region shown for ice optical thickness $\tau$ (d) and top altitude $z$ (e). Coastlines and geographic boundaries are coloured black. 

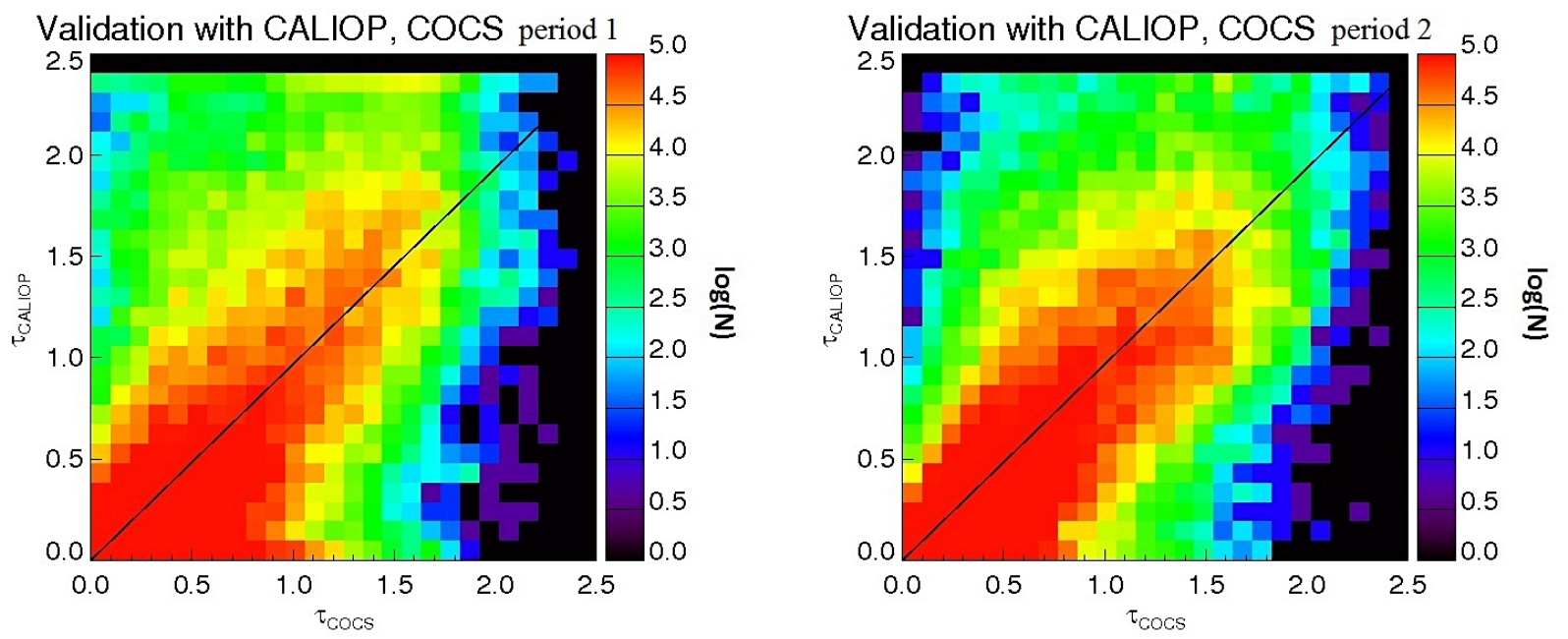

Figure 6. Scatter plot of the cirrus optical thickness $\tau$ of CALIOP and COCS: period 1 (left) and period 2 (right). Colours show the number of occurrences on a logarithmic scale.

values of $\tau_{\text {CALIOP }}$ is lower in COCS period 2 compared to COCS period 1 . For both periods, the standard deviation of $\tau, \sigma_{\tau}$ is calculated as

$\sigma_{\tau}=\sqrt{\frac{1}{N} \sum_{i=1}^{N}\left(\tau_{\mathrm{COCS}, i}-\tau_{\mathrm{CALIOP}, i}\right)^{2}}$,

where $N$ is the number of observations within the test data set, results in $\sigma_{\tau}=0.25$ for period 1 and $\sigma_{\tau}=0.24$ for period 2 , respectively. In relation to the natural variability this error is lower than $10 \%$ in both cases.

The validation of the cirrus top altitude $z_{\text {COCS }}$ for both periods compared to the results $z_{\text {CALIOP }}$ measured by CALIOP is depicted in Fig. 7. For altitudes $z_{\text {CALIOP }}$ between 10 and $15 \mathrm{~km}$ a high agreement between COCS and CALIOP is detected, while for low altitudes COCS overestimates the top altitude. For $z_{\text {CALIOP }}>15 \mathrm{~km}$ a slight underestimation of the cirrus top altitude is found on the left of Fig. 7 for COCS period 1 . The comparison of the top altitudes retrieved by COCS period 2 differs only slightly from the results of period 1 . The standard deviation for period 1 is calculated as $\sigma_{z}=708 \mathrm{~m}$ and $\sigma_{z}=756 \mathrm{~m}$ for period 2, while the natural range of top altitudes varies over more than $11 \mathrm{~km}$.

One reason for the resulting deviations is most likely the different resolutions of both instruments. In the case of broken clouds within the sampling area of SEVIRI (Fig. 8) it is possible on the one hand that CALIOP either misses retrieving the cirrus optical thickness and top altitude as derived by COCS, or even misses detecting a cirrus cloud. On the other hand inhomogeneous and probably thin cirrus clouds located in the SEVIRI sampling area and detected by CALIOP might have no significant influence on the brightness temperatures measured by SEVIRI and therefore are not detectable by COCS.
Two further characteristics of COCS are investigated for the final assessment of its sensitivity. First the detection efficiency, $\operatorname{eff}_{\operatorname{det}}(\tau)$, is determined for equidistant intervals of cirrus optical thickness $\Delta \tau=0.01$ :

$\operatorname{eff}_{\operatorname{det}}(\tau)=\frac{N_{\mathrm{COCS}}(\tau)}{N_{\mathrm{CALIOP}}(\tau)}$,

where $N_{\mathrm{COCS}}(\tau)$ is the number of pixels in which COCS detects a cirrus cloud, and $N_{\text {CALIOP }}(\tau)$ the number of pixels with a cirrus cloud detected by CALIOP. The second important property, the false alarm rate $\left(\tau=\tau_{\mathrm{COCS}}\right)$ describes the rate of false detections of COCS for an interval of optical thickness (again for $\Delta \tau=0.01$ ). It is calculated as

$\operatorname{far}(\tau)=\frac{N_{\mathrm{F}}(\tau)}{N_{\mathrm{H}}(\tau)+N_{\mathrm{F}}(\tau)}$,

with $N_{\mathrm{F}}(\tau)$ representing the number of pixels where COCS detects a cirrus cloud, while CALIOP detects no cirrus cloud. $N_{\mathrm{H}}(\tau)$ is the number of pixels where both COCS and CALIOP detect a cirrus cloud. The subscripts $\mathrm{H}$ and $\mathrm{F}$ are the abbreviations for Hits and False alarms respectively. In Fig. 9 the detection efficiencies (blue) of COCS period 1 (left) and period 2 (right) are depicted for the equidistant interval of $\Delta \tau=0.01$. The detection efficiency is found to show very high efficiencies of eff det $>95 \%$ for $\tau=0.01$, rising up to $\operatorname{eff}_{\operatorname{det}}=99.5 \%$ for $\tau \geq 1.0$. The false alarm rates of COCS period 1 and period 2 show different behaviours (Fig. 9 red). Both neural networks start with relatively high rates up to $\approx 25 \%$ for the false alarms at $\tau<0.1$, but show a rapid decrease in the false alarm rate in combination with high detection efficiencies for $\tau \geq 0.1$. The analyses for detection efficiency and false alarm rate of COCS are now used to define the limitation of the COCS algorithm. As a trade-off between sensitivity and accuracy, a threshold of $\tau_{\mathrm{COCS}} \geq 0.1$ 

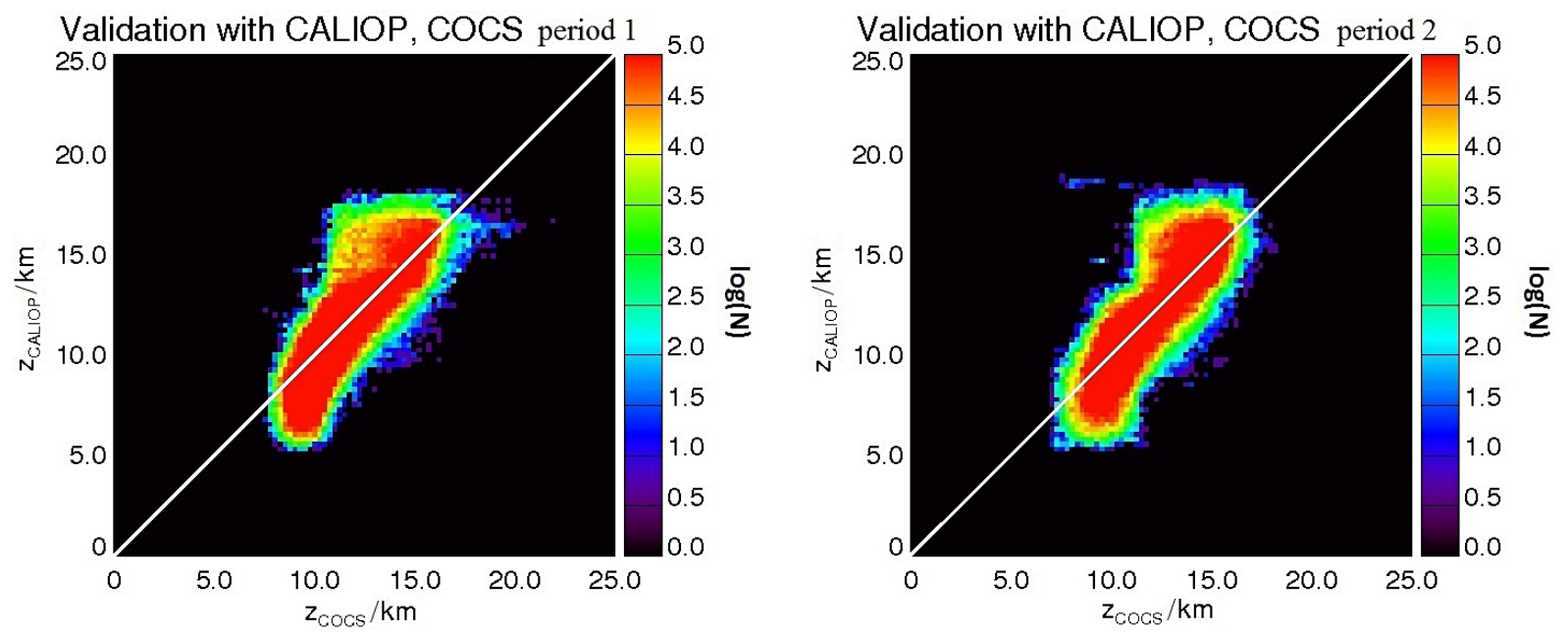

Figure 7. Scatter plot of the cirrus top altitude $z$ of CALIOP and COCS: period 1 (left) and period 2 (right). Colours show the number of occurrences on a logarithmic scale.

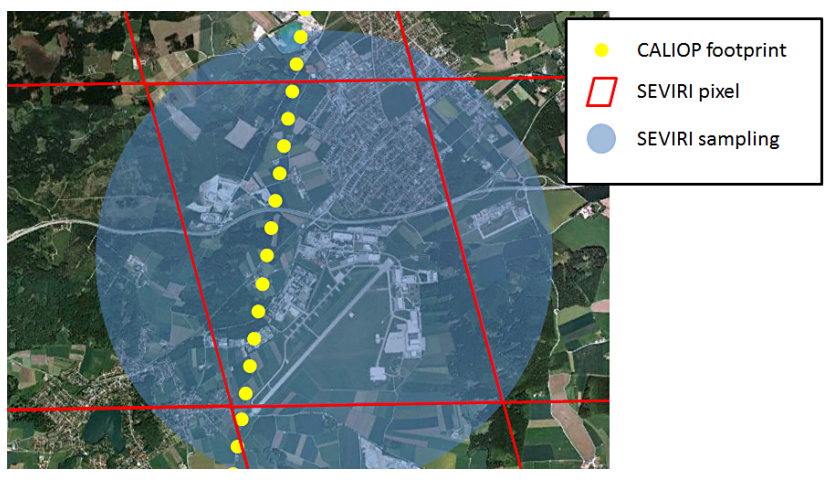

Figure 8. Schematic intercomparison of CALIOP single profile footprints (yellow circles) and SEVIRI pixels (red parallelograms). In blueish colour the sampling area of one SEVIRI pixel is sketched. Note that this is an exemplary plot to represent the different scales.

is selected. This lower boundary for the algorithm enables COCS to detect cirrus clouds with a very high detection efficiency of $97.41 \%$ for period 1 and $99.34 \%$ for period 2 in combination with a low false alarm rate of 5.05 and $4.80 \%$, respectively. Even with this restriction, COCS is still able to detect a wide range of thin cirrus clouds, which will become more obvious in the next section (Sect. 5.2).

\subsection{Airborne HSRL data}

In this section the cirrus ice optical thickness derived from the airborne HSRL described in detail in Wirth et al. (2009) is used. These data were measured during a flight within the DLR-project "PAZI" in autumn 2008, where, amongst other things, optical properties of thin cirrus and contrail cirrus were measured. The aim of the PAZI project at DLR was to better understand the formation of the ice phase in cirrus clouds from natural and anthropogenic aerosols and to improve microphysical and optical parametrizations of cirrus clouds in global models. In the following the validation of COCS with the HSRL is discussed, focusing on one specific flight on 18 October 2011. The DLR research aircraft, the Dassault Falcon, started at around 13:00 UTC at DLR, Oberpfaffenhofen, routing along the Alps, turning north along the Rhine valley, and finally heading east across Germany to Lindenberg. At 16:00 UTC the aircraft returned to Oberpfaffenhofen.

The HSRL is a lidar that works in general similar to CALIOP aboard CALIPSO. However, it calculates the atmospheric extinction and backscatter coefficients without assuming the lidar ratio, which is a great advantage. This type of lidar is able to directly measure the optical thickness of e.g. cirrus clouds (Wirth et al., 2009; Esselborn, 2008).

\subsubsection{Validation with HSRL}

In order to validate the results of COCS, the different spatial and temporal resolutions of the HSRL and the SEVIRI data have to be accounted for. The HSRL provides ice optical thickness at a $1 \mathrm{~s}$ temporal resolution, which is equivalent to a distance of $200 \mathrm{~m}$ assuming the true air speed of the Falcon with a very narrow footprint of $2 \mathrm{~m}$. Due to the high temporal and spatial resolution of the HSRL two points are important:

1. The geo-referenced position of the Falcon is used to identify the position of the clouds. The cloud top height is extracted from the HSRL profiles and is used for parallax correction and collocation.

2. The Rapid Scan Mode of SEVIRI is used by COCS leading to a temporal resolution of approximately $5 \mathrm{~min}$.

Thus, the SEVIRI pixel closest to the Falcon track shows a maximum temporal misregistration of $2.5 \mathrm{~min}$. The HSRL 

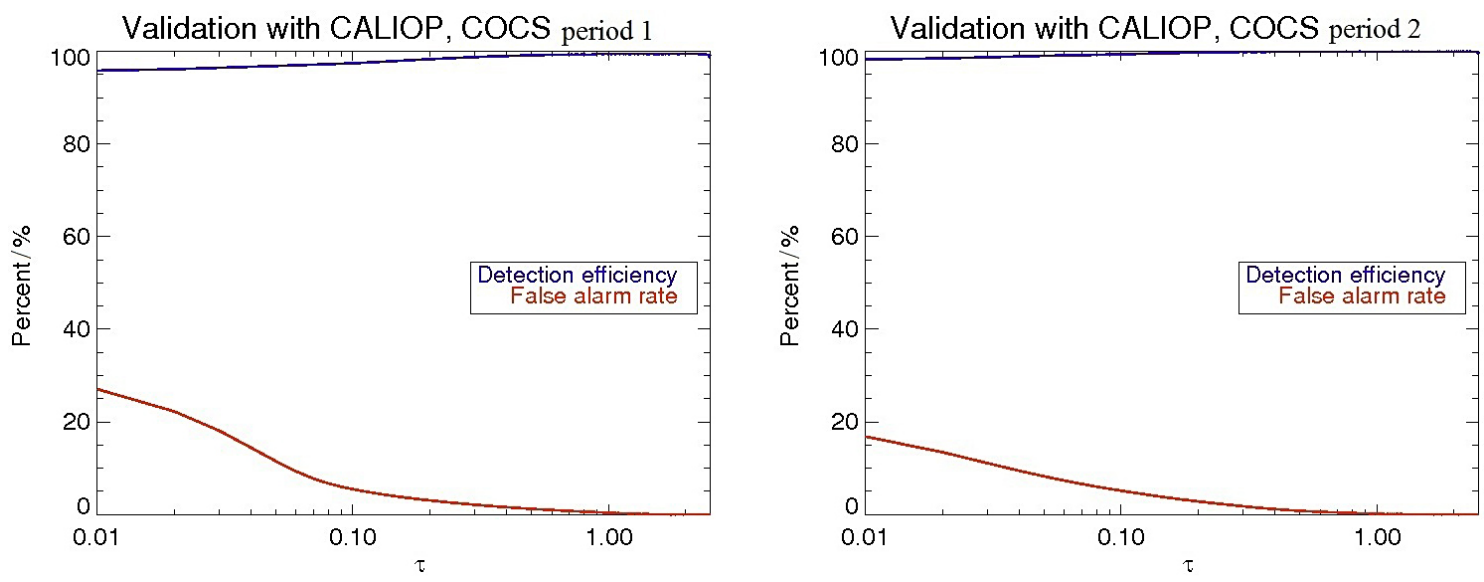

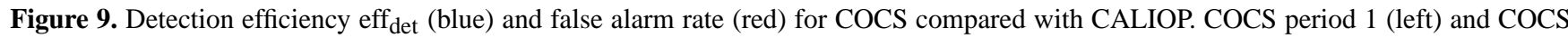
period 2 (right).

cirrus optical thickness $\tau_{\mathrm{HSRL}}$ for the SEVIRI pixels along the flight path is then calculated as the mean value of all HSRL measurements inside those pixels. This data set offers 394 SEVIRI pixels, which are now used to calculate the detection efficiency eff ${ }_{\text {det }}$ and the false alarm rate of COCS. At $\tau_{\mathrm{HSRL}}=0.2 \mathrm{COCS}$ already detects $80 \%$ of the cirrus clouds and eff $f_{\text {det }}$ increases for higher values of $\tau_{\mathrm{HSRL}}$. For $\tau_{\text {HSRL }}=0.1$ already $50 \%$ of the cirrus clouds are detected by both the HSRL and COCS. The false alarm rate amounts to $2.6 \%$ for all measured cirrus clouds. Finally, $\tau_{\mathrm{COCS}}$ and $\tau_{\mathrm{HSRL}}$ are plotted as a function of time in UTC in Fig. 10. The accordance to values of $\tau \leq 1.0$ is very good. Only a few pixels with higher values measured by the HSRL show underestimations of $\tau$ by COCS (especially around 14:00 UTC with $\tau$ reaching up to 2.5). A plausible reason for this behaviour can again be found in the different resolutions of both data sets. While COCS uses SEVIRI with its spatial resolution of approximately $4 \mathrm{~km} \times 5 \mathrm{~km}$ in mid-latitude regions, the HSRL data are averaged within one SEVIRI-pixel still with a cross-track resolution of around $2 \mathrm{~m}$. Especially after 14:05 UTC the curves of both optical thickness are found to be in very good agreement even in the case of multilayer clouds (water clouds and fog below cirrus clouds and layers).

\section{Optical depth derived with the COCS algorithm}

For the year 2010, the cirrus coverage derived by COCS is depicted in Fig. 11 at a resolution of $0.5^{\circ} \times 0.5^{\circ}$. The maximum cirrus coverage of up to $60 \%$ is found in the tropical belt mainly as a result of anvils produced directly by deep convection in the ITCZ and monsoonal circulations. This high coverage is present over Equatorial Central South America, Western Africa, Indonesia and the West-Central Pacific Oceanic warm pool.

A still high, but lower coverage is seen at the northern and southern mid-latitude storm tracks with values around $35 \%$.

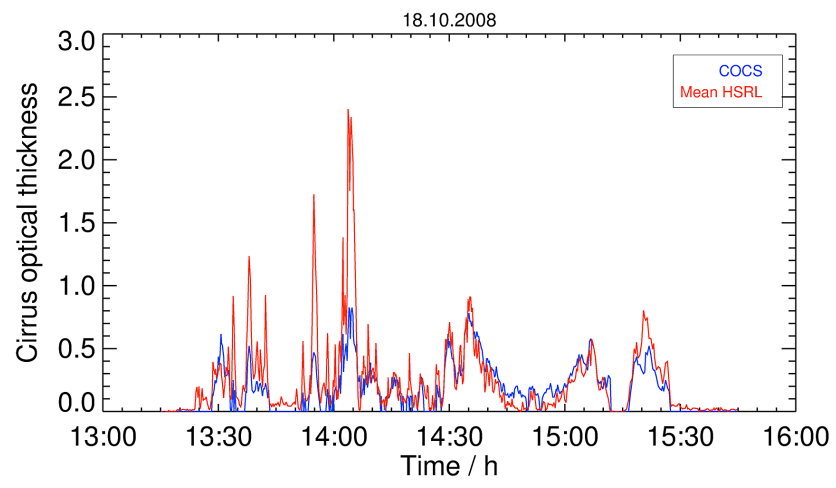

Figure 10. Cirrus optical thickness measured by COCS (blue) and by the HSRL (red) during the FALCON flight, 10 October 2008.

Desert-like regions of northern Africa, the Arabian Peninsula and southern Africa show rather low values of only 0 to $20 \%$. In opposition to the values derived by Sassen et al. (2008), especially the northern and southern Atlantic regions are found to have higher values at least for this time period with values around $40 \%$.

Based on a total of 5 years of processed COCS data with a temporal resolution of $15 \mathrm{~min}$ the diurnal cycle of different properties such as the cirrus ice optical thickness can be derived. An example of this is shown in Fig. 12 for the southern Africa region (SAC), defined as the orange box in Fig. 11 with limits at 30 to $20^{\circ} \mathrm{S}$ and 0 to $35^{\circ} \mathrm{E}$, and the Mediterranean region (MED), defined as the red box with limits at 30 to $40^{\circ} \mathrm{N}$ and 0 to $35^{\circ} \mathrm{E}$.

COCS detects a diurnal cycle dominated by convection in these two regions, depicted in Fig. 12.

For the SAC region the mean ice optical thickness of cirrus clouds is found to reach its maximum at around 15:00 LT with $\tau_{\max }=0.13$. The minimum is located at 07:00 LT with $\tau_{\min }=0.06$. Between minimum and maximum a very steep 


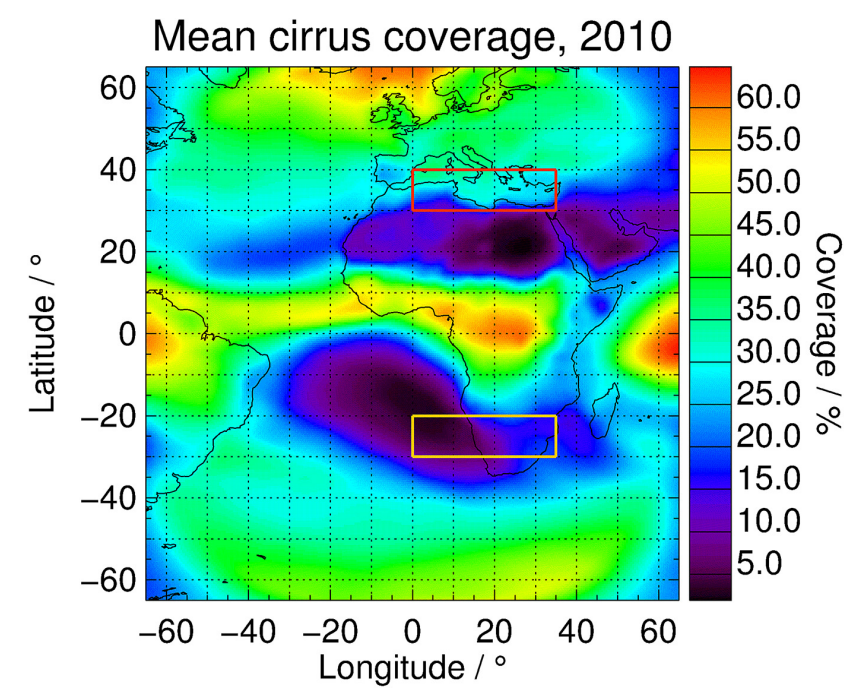

Figure 11. Mean cirrus coverage for the year 2010 at a resolution of $0.5^{\circ} \times 0.5^{\circ}$ derived by COCS with the southern Africa region (SAC, orange box) and the Mediterranean region (MED, red box).

increase of the mean ice optical thickness is observed. After the maximum in the afternoon is reached $\tau$ decreases during evening and night until its minimum. The MED region shows a different diurnal cycle with a maximum of $\tau_{\max }=0.14$. These high values are found at 16:00 LT until the evening. Afterwards the ice optical thickness decreases slowly until its minimum at 10:00 LT with $\tau_{\min }=0.12$. During the morning $\tau$ rises again. So, differences between both regions occur in the comparison of the mean ice optical thickness. In the MED region the maximum of the mean ice optical thickness is reached earlier than in the SAC region. The MED region also shows a generally lower mean ice optical thickness for the whole diurnal cycle. In the SAC region a steeper increase of $\tau$ after the minimum is observed compared to the MED, while the decrease during night is shallower than in the MED region.

\section{Conclusions}

In this paper a detailed description of the Cirrus Optical properties derived from CALIOP and SEVIRI during day and night (COCS) algorithm is presented. With the high sensitivity and the high vertical resolution of active remote sensing such as the lidar CALIOP aboard CALIPSO the observation of even subvisible cirrus clouds is possible. Due to its polar orbit with a repeat cycle of 16 days an observation of formation and dissipation of cirrus clouds is not possible. Therefore the COCS algorithm combines the advantages of CALIOP (high sensitivity and high vertical resolution) with the high temporal and good spatial resolution of the geostationary instrument SEVIRI aboard MSG. Since COCS utilizes only the thermal infrared channels of SEVIRI day and

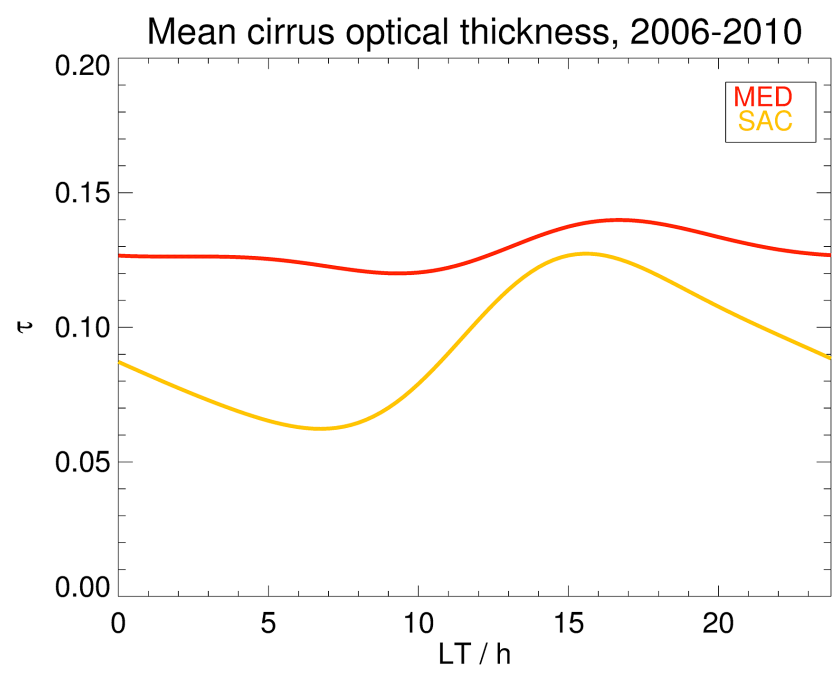

Figure 12. Mean ice optical thickness at a $15 \mathrm{~min}$ temporal resolution in the convective dominated regions MED (red) and SAC (yellow).

night time observations of cirrus coverage, optical thickness, and top altitude are now possible.

The utilization of a backpropagation neural network replaces fixed threshold values and results in a very flexible interpretation of the different thermal brightness temperatures and their differences by the neural network, which results in a very accurate retrieval of the cirrus properties derived by COCS.

The validation of COCS has proven that it is well suited to detect thin cirrus clouds and to derive their ice optical thickness and top altitude at a temporal resolution of $15 \mathrm{~min}$ accurately with high detection efficiencies (up to $98 \%$ at $\tau=0.1$ ) and low false alarm rates $(\sim 5 \%$ at $\tau=0.1)$. The standard deviations were calculated as $\sigma_{\tau}=0.25$ for cirrus ice optical thickness and $\sigma_{z}=750 \mathrm{~m}$ for cirrus top altitude. Another advantage is the low runtime of around $600 \mathrm{~s}$ for one full MSG disc with $3712 \times 3712$ pixels on a common office computer. In this work the COCS algorithm was validated with an independent data set of coincident measurements of CALIOP and SEVIRI as well as with measurements of an airborne High Spectral Resolution Lidar. The validation with CALIOP indicated a high detection efficiency of up $99 \%$ combined with a low false alarm rate of less than $5 \%$ for cirrus optical thickness of $\tau \geq 0.1$. Furthermore, the comparison with the airborne measurements of cirrus optical thickness during the PAZI campaign in autumn 2008 showed very good agreement in terms of retrieving cirrus optical thickness and detecting cirrus clouds with a low false alarm rate and a high detection efficiency compared to hitherto existing cirrus cloud retrievals. For example the METEOSAT Cirrus Detection Algorithm (MECiDA) based on different morphological and threshold tests detects was found to have a significantly lower detection efficiency of $25 \%$ at $\tau=0.1$ by similar false alarm 
rates compared to the same measurements of the airborne HSRL. For the first time, a data set derived by a passive geostationary satellite containing the optical thickness and top altitude of optically thin cirrus clouds $(\tau \geq 0.1)$ with very high temporal resolution, good spatial resolution, high sensitivity and high accuracy could be produced. However, the retrieval of ice optical thickness is limited to $\tau=2.5$, since the backscatter signal of the spaceborne lidar CALIOP used for the training data set gets attenuated and is therefore unable to penetrate thicker clouds.

Acknowledgements. This paper is dedicated to our dear colleague, mentor, and good friend Hermann Mannstein, who died far too young in January 2013. Without his endless discussions, creative mind, great scientific knowledge, technical skills, and guidance this work would not have been possible. With his work on spaceborne remote sensing of cirrus and contrail cirrus clouds he inimitably contributed to atmospheric research more than three decades.

Special thanks goes to Ulrich Schumann and Martin Wirth for performing the PAZI Falcon campaign and to Martin Wirth for providing the HSRL data from this flight.

CALIOP/CALIPSO data were obtained from the NASA Langley Research Atmospheric Science Data Center. I would like to thank the CALIPSO science team for providing these data.

The service charges for this open access publication have been covered by a Research Centre of the Helmholtz Association.

Edited by: A. Macke

\section{References}

Ackerman, T. P., Liou, K.-N., Valero, F. P. J., and Pfister, L.: Heating Rates in Tropical Anvils, J. Atmos. Sci., 45, 1606-1623, doi:10.1175/1520-0469(1988)045<1606:HRITA>2.0.CO;2, 1988.

Aires, F., Prigent, C., Rossow, W. B., and Rothstein, M.: A new neural network approach including first guess for retrieval of atmospheric water vapor, cloud liquid water path, surface temperature, and emissivities over land from satellite microwave observations, J. Geophys. Res., 106, 14887-14907, doi:10.1029/2001JD900085, 2001.

Bailey, M. and Hallett, J.: Ice Crystal Linear Growth Rates from $-20^{\circ}$ to $-70^{\circ} \mathrm{C}$ : Confirmation from Wave Cloud Studies, J. Atmos. Sci., 69, 390-402, doi:10.1175/JAS-D-11-035.1, 2012.

Blackwell, W. J.: A neural-network technique for the retrieval of atmospheric temperature and moisture profiles from high spectral resolution sounding data, IEEE T. Geosci. Remote, 43, 25352546, doi:10.1109/TGRS.2005.855071, 2005.

Bugliaro, L., Zinner, T., Keil, C., Mayer, B., Hollmann, R., Reuter, M., and Thomas, W.: Validation of cloud property retrievals with simulated satellite radiances: a case study for SEVIRI, Atmos. Chem. Phys., 11, 5603-5624, doi:10.5194/acp-11-5603-2011, 2011.
Chen, T., Rossow, W. B., and Zhang, Y.: Radiative Effects of CloudType Variations, J. Climate, 13, 264-286, doi:10.1175/15200442(2000)013<0264:REOCTV>2.0.CO;2, 2000.

Esselborn, M.: Lidar-Messung der Extinktion des atmosphärischen Aerosols am Beispiel der Feldstudie SAMUM-1, Dissertation, Ludwig-Maximilians-Universität München, 2008.

EUMETSAT: A Planned Change to the MSG Level 1.5 Image Product Radiance Definition, Tech. Rep. January, Darmstadt, Germany, 2007.

Ewald, F., Bugliaro, L., Mannstein, H., and Mayer, B.: An improved cirrus detection algorithm MeCiDA2 for SEVIRI and its evaluation with MODIS, Atmos. Meas. Tech., 6, 309-322, doi:10.5194/amt-6-309-2013, 2013.

Graf, K., Schumann, U., Mannstein, H., and Mayer, B.: Aviation induced diurnal North Atlantic cirrus cover cycle, Geophys. Res. Lett., 39, L16804, doi:10.1029/2012GL052590, 2012.

Hlavka, D. L., Yorks, J. E., Young, S. A., Vaughan, M. A., Kuehn, R. E., McGill, M. J., and Rodier, S. D.: Airborne validation of cirrus cloud properties derived from CALIPSO lidar measurements: Optical properties, J. Geophys. Res., 117, D09207, doi:10.1029/2011JD017053, 2012.

Hu, Y., Winker, D., Vaughan, M., Lin, B., Omar, A., Trepte, C., Flittner, D., Yang, P., Nasiri, S. L., Baum, B., Holz, R., Sun, W., Liu, Z., Wang, Z., Young, S., Stamnes, K., Huang, J., and Kuehn, R.: CALIPSO/CALIOP Cloud Phase Discrimination Algorithm, J. Atmos. Ocean. Tech., 26, 2293-2309, doi:10.1175/2009JTECHA1280.1, 2009.

Inoue, T.: On the temperature and effective emissivity determination of semi-transparent cirrus clouds by bi-spectral measurements in the $10 \mu \mathrm{m}$ window region, J. Meteorol. Soc. Jpn., 63, 88-99, 1985.

Kaiser-Weiss, A.: Group for High Resolution Sea Surface Temperature, https://www.ghrsst.org/data/ghrsst-data-tools/ navo-ghrsst-pp-land-sea-mask/, 2011.

Krebs, W., Mannstein, H., Bugliaro, L., and Mayer, B.: Technical note: A new day- and night-time Meteosat Second Generation Cirrus Detection Algorithm MeCiDA, Atmos. Chem. Phys., 7, 6145-6159, doi:10.5194/acp-7-6145-2007, 2007.

Liou, K.-N.: Remote Sensing of the Thickness and Composition of Cirrus Clouds from Satellites, J. Appl. Meteorol., 16, 91-99, doi:10.1175/1520-0450(1977)016<0091:RSOTTA>2.0.CO;2, 1977.

Liou, K. N.: An introduction to atmospheric radiation, International geophysics series, 2, 84 edn., 2002.

Lynch, D., Sassen, K., Starr, D., and Stephens, G.: Cirrus: History and definitions, Oxford Univ. Press, New York, 2002.

Meerkötter, R., Schumann, U., Doelling, D. R., Minnis, P., Nakajima, T., and Tsushima, Y.: Radiative forcing by contrails, Ann. Geophys., 17, 1080-1094, doi:10.1007/s00585-999-10807, 1999.

Menzel, W. P., Smith, W. L., and Stewart, T. R.: Improved Cloud Motion Wind Vector and Altitude Assignment Using VAS, J. Clim. Appl. Meteorol., 22, 377-384, doi:10.1175/1520 0450(1983)022<0377:ICMWVA>2.0.CO;2, 1983.

Mioche, G., Josset, D., Gayet, J.-F., Pelon, J., Garnier, A., Minikin, A., and Schwarzenboeck, A.: Validation of the CALIPSOCALIOP extinction coefficients from in situ observations in midlatitude cirrus clouds during the CIRCLE-2 experiment, J. Geophys. Res., 115, D00H25, doi:10.1029/2009JD012376, 2010. 
Nakajima, T. and King, M. D.: Determination of the Optical Thickness and Effective Particle Radius of Clouds from Reflected Solar Radiation Measurements. Part I: Theory, J. Atmos. Sci., 47, 1878-1893, doi:10.1175/15200469(1990)047<1878:DOTOTA>2.0.CO;2, 1990.

Nazaryan, H., McCormick, M. P., and Menzel, W. P.: Global characterization of cirrus clouds using CALIPSO data, J. Geophys. Res., 113, D16211, doi:10.1029/2007JD009481, 2008.

Palm, S. P.: Validation of ECMWF global forecast model parameters using GLAS atmospheric channel measurements, Geophysi. Res. Lett., 32, L22S09, doi:10.1029/2005GL023535, 2005.

Radová, M. and Seidl, J.: PARALLAX APPLICATIONS WHEN COMPARING RADAR AND, in: 2008 EUMETSAT Meteorological Satellite Conference, Darmstadt, Germany, 2008.

Rogers, R. R., Hostetler, C. A., Hair, J. W., Ferrare, R. A., Liu, Z., Obland, M. D., Harper, D. B., Cook, A. L., Powell, K. A., Vaughan, M. A., and Winker, D. M.: Assessment of the CALIPSO Lidar $532 \mathrm{~nm}$ attenuated backscatter calibration using the NASA LaRC airborne High Spectral Resolution Lidar, Atmos. Chem. Phys., 11, 1295-1311, doi:10.5194/acp-11-12952011, 2011.

Rossow, W. B. and Schiffer, R.: Advances in understanding clouds from ISCCP, B. Am. Meteorol. Soc., 80, 2261-2287, 1999.

Rumelhart, D. E., Hinton, G. E., Williams, R. J., and Group, P. D. P. R.: Learning representations by back-propagating errors, in: Parallel Distributed Processing: Explorations in the Microstructure of Cognition, Vol. I, edited by: Rumelhart, D. E. and Mc Clelland, J. L., chap. 8, 318-362, MIT Press, Cambridge, Mass., 1986.

Sassen, K., Wang, Z., and Liu, D.: Global distribution of cirrus clouds from CloudSat/Cloud-Aerosol Lidar and Infrared Pathfinder Satellite Observations (CALIPSO) measurements, J. Geophys. Res., 113, D00A12, doi:10.1029/2008JD009972, 2008.

Schmetz, J., Pili, P., Tjemkes, S., Just, D., Kerkmann, J., Rota, S., and Ratier, A.: An introduction to Meteosat Second Generation (MSG), B. Am. Meteorol. Soc., 83, 977-992, doi:10.1175/BAMS-83-7-Schmetz-1, 2002.

Schumann, U., Mayer, B., Graf, K., and Mannstein, H.: A Parametric Radiative Forcing Model for Contrail Cirrus, J. Appl. Meteorol. Clim., 51, 1391-1406, doi:10.1175/JAMC-D-11-0242.1, 2012.

Stubenrauch, C. J., Chédin, A., Rädel, G., Scott, N. A., and Serrar, S.: Cloud Properties and Their Seasonal and Diurnal Variability from TOVS Path-B, J. Climate, 19, 5531-5553, doi:10.1175/JCLI3929.1, 2006.

Stubenrauch, C. J., Rossow, W. B., Kinne, S., Ackerman, S., Cesana, G., Chepfer, H., Di Girolamo, L., Getzewich, B., Guignard, a., Heidinger, a., Maddux, B. C., Menzel, W. P., Minnis, P., Pearl, C., Platnick, S., Poulsen, C., Riedi, J., Sun-Mack, S., Walther, a., Winker, D., Zeng, S., and Zhao, G.: Assessment of Global Cloud Datasets from Satellites: Project and Database Initiated by the GEWEX Radiation Panel, B. Am. Meteorol. Soc., 94, 1031-1049, doi:10.1175/BAMS-D-12-00117.1, 2013.
Szejwach, G.: Determination of Semi-Transparent Cirrus Cloud Temperature from Infrared Radiances: Application to METEOSAT, J. Appl. Meteorol., 21, 384-393, doi:10.1175/15200450(1982)021<0384:DOSTCC>2.0.CO;2, 1982.

Vaughan, M., Winker, D., and Powell, K.: CALIOP Algorithm Theoretical Basis Document, Part 2: Feature Detection and Layer Properties Algorithms, Tech. Rep. Algorithm Theoretical Basis Document No. PC-SCI-202 Part 2, NASA Langley Research Center, Hampton, Virginia, USA, 2005.

Vaughan, M., Kuehn, R. E., Young, S., McGill, M. J., Liu, Z., and Hu, Y.: Validating Cirrus Clouds Optical Properties retrieved by CALIPSO, in: 24th International Lidar Radar Conference, 10901093, Boulder, Colorado, USA, 2008.

Vaughan, M. A., Young, S., Winker, D. M., Powell, K., Omar, A., Liu, Z., Hu, Y., and Hostetler, C.: Fully automated analysis of space-based lidar data: an overview of the CALIPSO retrieval algorithms and data products, Proc. of SPIE, 5575, 16-30, doi:10.1117/12.572024, 2004.

Weickmann, H.: Formen und Bildung atmoshärischer Eiskristalle, Beitr. Phys. Atmosph., 28, 12-52, 1945.

Wielicki, B. A. and Parker, L.: On the determination of cloud cover from satellite sensors: The effect of sensor spatial resolution, J. Geophys. Res., 97, 799-823, 1992.

Winker, D., Getzewich, B., and Vaughan, M.: Cloud Properties from CALIPSO / CALIOP, in: GEWEX Cloud Assesment, June, Berlin, Germany, 2010.

Winker, D. M., Pelon, J., and Mc Cormick, M. P.: The CALIPSO mission: Spaceborne lidar for observation of aerosols and clouds, in: Proc. of SPIE - Lidar Remote Sensing for Industry and Environment Monitoring III, Vol. 4893, 24-25, Hangzhou, China, 2002.

Winker, D. M., Hunt, W. H., and McGill, M. J.: Initial performance assessment of CALIOP, Geophysi. Res. Lett., 34, L19803, doi:10.1029/2007GL030135, 2007.

Winker, D. M., Vaughan, M. A., Omar, A., Hu, Y., Powell, K. A., Liu, Z., Hunt, W. H., and Young, S. A.: Overview of the CALIPSO Mission and CALIOP Data Processing Algorithms, J. Atmos. Ocean. Tech., 26, 2310-2323, doi:10.1175/2009JTECHA1281.1, 2009.

Wirth, M., Fix, a., Mahnke, P., Schwarzer, H., Schrandt, F., and Ehret, G.: The airborne multi-wavelength water vapor differential absorption lidar WALES: system design and performance, Appl. Phys. B, 96, 201-213, doi:10.1007/s00340-009-3365-7, 2009.

Wylie, D., Piironen, P., Wolf, W., and Eloranta, E.: Understanding Satellite Cirrus Cloud Climatologies with Calibrated Lidar Optical Depths, J. Atmos. Sci., 52, 4327-4343, doi:10.1175/15200469(1995)052<4327:USCCCW>2.0.CO;2, 1995.

Wylie, D. P. and Menzel, W. P.: Two Years of Cloud Cover Statistics Using VAS, J. Climate, 2, 380-392, doi:10.1175/15200442(1989)002<0380:TYOCCS>2.0.CO;2, 1989.

Wylie, D. P. and Menzel, W. P.: Eight years of high cloud statistics using HIRS, J. Climate, 12, 170-184, 1998. 